\title{
PENGETAHUAN DAN PEMAHAMAN DINI NARKOBA DAN ZAT ADITIF PADA GENERASI MUDA SEBAGAI ASET BANGSA DI DESA MENGWI BADUNG
}

\author{
N.M. Suaniti ${ }^{1}$ I N. Wirajana ${ }^{2}$, N.K. Ariati $^{3}$ dan M. Manurung ${ }^{4}$
}

\begin{abstract}
ABSTRAK
Era globalisasi sebagai suatu peluang dan tantangan kaum muda Indonesia untuk berpartisipasi aktif memperoleh hal-hal yang tidak baik, salah satunya memahami pengetahuan awal tentang obat dan zat aditif yang memungkinkan dapat menyesatkan generasi muda. Drugs (narkotika dan obat / bahan berbahaya lainnya) dikenal sebagai obat-obatan yang disalahgunakan (narkotika, psikotropika dan zat adiktif lainnya) oleh Kementerian Kesehatan Republik Indonesia yang merujuk pada sekelompok senyawa yang umumnya memiliki risiko penambahan bagi pengguna. Selanjutnya, aditif makanan juga bisa menyebabkan keracunan. Badung adalah salah satu bagian dari dunia di mana tujuan wisata desa Mengwi menghubungkan daerah utara dan selatan menjadi rentan terhadap efek dari upaya pencegahan yang dilakukan sehingga salah satunya dengan memberikan pengetahuan obat-obatan dan aditif oleh otoritas yang relevan. Metode ini dilakukan dengan memberikan kuliah dan sesi tanya jawab dengan mengisi kuesioner pre dan posttest. Hasil kuesioner dianalisis dan menunjukkan peningkatan pemahaman obat dan aditif secara signifikan untuk menyebar secara merata pada generasi muda di desa Mengwi setelah kegiatan, tetapi kegiatan pendidikan ini perlu dilakukan secara berkala di setiap banjar dan diperluas di komunitas pedesaan lainnya. di Bali.
\end{abstract}

Kata kunci : aditif, generasi muda, narkotika, pengetahuan dini, psikotropika

\begin{abstract}
The era of globalization is an opportunity and challenges Indonesian youths to participate actively obtain in things that are not good, one of them understood early knowledge of drugs and additives that enable the younger generation can be misleading. Drugs (narcotics and drug/ hazardous materials) with another term drug (narcotics, psychotropic and other addictive substances) by the Ministry of Health of the Republic of Indonesia refers to a group of compounds generally have a risk of addition for users. Furthermore, food additives can also cause poisoning. Badung is one of part of the world where tourist destinations Mengwi village is connecting northern and southern regions become vulnerable to the effects of prevention efforts of undertaken so that one of them by giving lectures drugs and additives by the relevant authorities. The method is performed by giving a lecture and question and answer session with filling out the questionnaire pre and posttest. The results of the questionnaire were analyzed and showed an increase understanding of drugs and additives significantly to the spread evenly on the younger generation in Mengwi village after the activity, but this dedication activities need to be carried out periodically in each row and expanded in other rural communities in Bali
\end{abstract}

Keywords: additives, early knowledge narcotic, psikotropic, youth

1,2,3,4 Staf pengajar Program Studi Kimia, Fakultas Matematika dan Ilmu Pengetahuan Alam, Universitas Udayana, ${ }^{1}$ Email: madesuaniti@unud.ac.id 


\section{PENDAHULUAN}

Narkoba (Narkotika dan Bahan berbahaya) atau NAPZA (Narkotika, Psikotropika, dan zat adiktif lainnya) dari tahun ketahun semakin meningkat, sementara fenomenanya sendiri bagaikan gunung es (ice berg) artinya yang tampak di permukaan lebih kecil dibandingkan dengan yang tidak tampak. Pemerintah menyatakan bahwa angka penyalahgunaan NAPZA 130.000 orang atau 0,065\% dari jumlah penduduk Indonesia 200 juta orang berdasarkan INPRES 6/71, 1995 (Hawari, 2001).Angka sebenarnya adalah 10 kali lipat dari angka resmi (dark number $=10)$ artinya bila ditemukan satu orang penyalahgunaan NAPZA ada 10 orang lainnya yang tidak terdata resmi.

Istilah Narkoba sesuai dengan surat edaran Badan Narkotika Nasional (BNN) No. SE/03/IV/2002, merupakan akronim dari Narkotika (Undang-Undang RI Nomor 22 tahun 1997, contohnya adalah ganja, opium, morfin dan kodein) (Riyanto, 2001), Psikotropika (Undang-undang RI No.5 tahun 1997, contohnya ekstasi, shabu-shabu, amfetamin, efedrin, pentobarbital, Flunitrazepam, dan diazepam, bromazepam, klonazepam, klordiazepoxide, nitrazepam (Lowry and Garriot, 1979; Japardi, 2002).Narkoba merupakan suatu obat yang bila digunakan untuk tujuan indikasi medis (pengobatan), namun bila disalahgunakan diistilahkan dengan drug abuse, yang dapat mengubah pikiran, suasana hati atau perasaan, dan perilaku seseorang (Nasution, 2007).

Narkotika dan Psikotropika disebutkan sebagai drugs of abuse (obat-obatan yang disalahgunakan) seperti morfin, opium, barbiturat, metadon, amfetamin, efedrin, ketamine, alkilnitrat (Moffat et al., 2004). Narkoba atau napza, mengacu pada kelompok senyawa yang umumnya memiliki risiko kecanduan bagi penggunanya.Menurut pakar kesehatan, narkoba sebenarnya adalah senyawasenyawa psikotropika yang biasa dipakai untuk membius pasien saat hendak dioperasi atau obatobatan untuk penyakit tertentu.Namun kini persepsi itu disalahartikan akibat pemakaian di luar peruntukan dan dosis yang semestinya. Sifat fisik, kimia, dan struktur kimia obat-obatan yang disalahgunakan untuk kepentingan toksikologi forensik sesuai Lowry and Garriot (1979). Analisis skrening obat yang disalahgunakan secara rutin dikerjakan di laboratorium forensik dengan Gas Chromatography (GC) dan secara konfirmasi dengan Infra red (IR) dan Mass Spectrometry(MS) sehingga alat nya dikenal sebagai GC-FTIR dan GCMS (Math, 1990).

Zat Adiktif lainnya adalah zat yang berpengaruh psikoaktif selain Narkotika dan Psikotropika seperti alkohol, tembakau, dan kafein. Kasus alkohol semakin banyak, yaitu meminum minuman keras sebagai wujud tindakan yang "belogajum" (bertindak bodoh dan sombong).Gubernur Bali Made Mangku Pastika menyampaikan rasa keprihatinannya menyusul korban jiwa akibat pestaminum arak oplosan di Pulau Dewata terus bertambah. Demikian halnya zat aditif (zat tambahan makanan) banyak sekali jenisnya, contohnya adalah pewarna, pengawet, pemanis, dan penyedap makanan yang dapat diperoleh secara alami dan sintetik. Pengetahuan zat kimia sintetik sering disalahgun akan akibat ketidaktahuan efeknya dalam waktu jangka panjang, belum dipahami bahwa zat aditif alami jauh lebih baik dari pada zat sintetik, namun zat aditif sintetik seringkali ditambahkan dan dicampurkan pada waktu pengolahan makanan baik secara sengaja maupun tidak sengaja. Mungkin juga masuknya zat-zat aditif initerjadi saat pengolahan, pengemasan, atau sudah terbawa oleh bahan-bahan kimia yang dipakai. Semua zat sintetik ini memungkinkan dapat menimbulkan keracunan.

Merdeka.com - Tewasnya Australia, Liam Davies (19) karena keracunan arak ilegal di Lombok, Nusa Tenggara Barat, pada 5 Januari lalu, masih menyisakan duka mendalambagi orang tuanya, Tim Davies. Priaasal Australia inipun berkeinginan untuk mendirikan organisasi LIAM (Lifesaving Initiative Against Methanol) Charitable Fund, yang bertujuan untuk mengkampanyekan anti arak oplosan di Indonesia

Berdasarkan hal ini maka suatu upaya pencegahan sering dilakukan oleh pemerintah melalui gerakan nasional memberantas narkoba. Untuk mendukung gerakan ini maka dilakukan suatu 
pengabdian mengenai pengetahuan kimia di desa Mengwi, selanjutnya untuk menganalisis Tingkat pemahaman dini dilakukan penyebaran kuesioner

\section{METODE PELAKSANAAN}

Secara umum khalayak sasaran kegiatan ini adalah karang taruna desa khususnya generasi muda di Desa Mengwi Kecamatan Mengwi Badung, yang merupakan salah satu bagian dari destinasi wisata Dunia. Desa Mengwi merupakan penghubung Wilayah Utara dan Selatan menjadi rentan akan pengaruhnya. Pengabdian ini terlaksana secara bersama-samase bagai program desa di desa Mengwi Badung dan hibah Udayana mengabdi dari Universitas Udayana melalui hibah pengabdian LPPM Universitas Udayana tahun 2016.

Dukungan kegiatan penyuluhan ini dari Bapak kepala Desa dan Pimpinan Badan Narkotika Nasional Kabupaten Badung untuk dapat secara bersama-sama melaksanakan penyuluhan mengenai narkoba sebagai upaya pencegahan penyalahgunaannya. Hasil yang diperoleh generasi muda desa Mengwi memiliki pemahaman dini tentang bahaya narkoba dan mengetahui efeknya dalam waktu lama melalui penjelasan dengan Gambar yang ditampilkan saat persentasi dari BNNK Badung, Oleh karena itu pengabdian ini penting dilakukan secara berkelanjutan agar generasi muda sebagai usia produktif memiliki bekal untuk membangun desanya hidup sehat dan sejahtera sebagai tumpuan dan harapan bangsa Indonesia.

Metode pelaksanaan pengabdian kepada masyarakat yaitu dengan cara menyebarkan kuisioner awal selanjutnya ceramah dari Narasumber BNNK Badung dibantu dari TIM pengabdian Universitas Udayana dan tanya jawab. Terakhir kembali dibagikan kuisioner. Untuk mengetahui peningkatan pemahaman mengenai narkoba dan zat aditif.

\section{HASIL DAN PEMBAHASAN}

Struktur kimia narkoba (Narkotika contohnya kokain, ganja, dan morfin. Psikotropika contohnya amfetamin, ekstasi, dan metamfetamin. Zat adiktif lainnya adalah nikotin, alkohol, dan kafein, dengan struktur seperti diperlihatkan dalam Gambar 1.

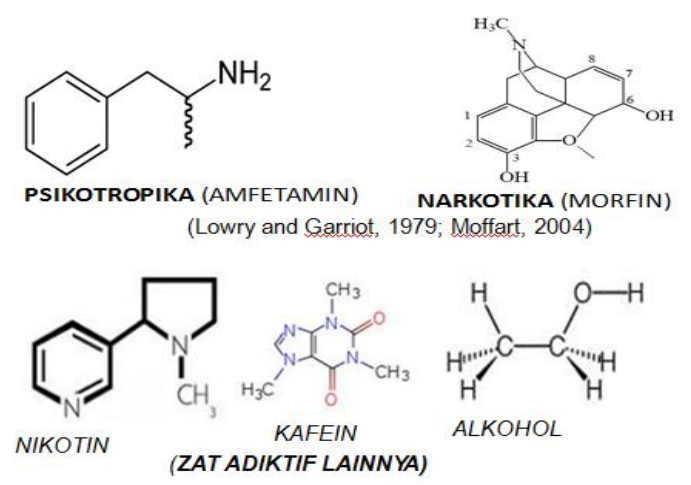

Gambar 1. Struktur Kimia Narkoba dan Zat Adiktif

Morfin sebagai salah satu senyawa narkotika, dengan kandungan utama opium/candu yang diperoleh dari tumbuhan Papaver Somniferum. Secara kimia, morfin adalah sekelompok alkaloid yang termasuk derivat fenantren. Dalam Farmakologi morfin merupakan obat yang berkhasiat 
untuk menghilangkan rasa (analgetik narkotik). Kata morfin sering dihubungkan dengan penyalahgunaan dengan kejadian yang sangat luas di dunia saat ini, yang berakibat timbulnya efek samping yang serius yang disebabkan karena keracunan morfin. Keracunan morfin dapat terjadi secara akut dan secara kronis. Keracunan akut biasanya terjadi akibat percobaan bunuh diri atau dosis yang berlebihan. Keracunan kronis terjadi akibat pemakaian berulang-ulang dan inilah yang sering terjadi. Adiksi (kecanduan) atau "morfinisme" tidak lain dari pada suatu keadaan keracunan kronis. Adiksi morfin ditandai dengan adanya habituasi, ketergantungan fisik dan toleransi. Gejalanya antara lain merasa sakit, iratabilitas, tremor, lakrimasi, berkeringat, menguap, bersinbersin, anoreksia, midriasis, deman, pernafasan cepat, muntah-muntah, kolik, diare dan pada akhirnya penderita mengalami dehidrasi, ketosis, asidosis, kolaps kardiovackuler yang bisa berakhir dengan kematian.

Morfin dapat diabsorpsi oleh usus, tetapi efek analgetik yang tinggi diperoleh melalui parentral. Dari satu dosis morfin, sebanyak $10 \%$ tidak diketahui nasibnya, sebagian mengalami konyugasi dengan asam glukoronat di hepar dan sebagian dikeluarkan dalam bentuk bebas. Ekskresi morfin terutama melalui ginjal. Urine mengandung bentuk bebas dan bentuk konyugasi. Berdasarkan hal ini, dapat dilakukan identifikasi morfin dalam urine dari penderita yang diduga keracunan morfin.

Metamfetamin sebagai salah satu senyawa Psikotropika, di metabolisme terutama di hati melalui beberapa jalur, antara lain : (i) N-Demetilasi menghasilkan amfetamin yang dikatalisasi oleh sitokrom P450 2D6; (ii) hidroksilasi aromatik oleh sitokrom P450 2D6, menghasilkan 4hidroksimetamfetamin; dan (iii) B-hidroksilasi yang menghasilkan norephedrine. Sekitar $70 \%$ dari metamfetamin yang diekskresikan melalui urin dalam 24 jam: $30-50 \%$ dalam bentuk metamfetamin, $15 \%$ dalam bentuk 4-hidroksimetamfetamin dan $10 \%$ dalam bentuk amfetamin (Gambar 2).

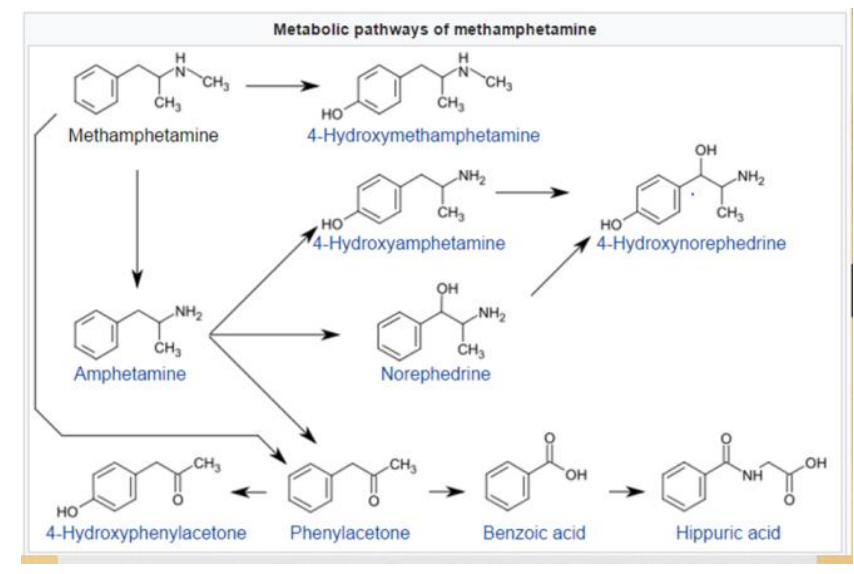

Gambar 2. Metabolisme metamfetamin

Spektrum FTIR dan contoh cara interpretasi gugus fungsi senyawa metamfetamin (Gambar 3) mengandung gugus fungsi $\mathrm{N}-\mathrm{H}$ amina, $\mathrm{C}-\mathrm{H}$ alkana, $\mathrm{C}=\mathrm{C}$ aromatik, $\mathrm{C}-\mathrm{H}$ alkana dan $\mathrm{C}-\mathrm{H}$ aromatik, kesemua gugus fungsi tersebut menunjukkan bahwa narkoba jenis I adalah jenis methamphetamin. SIfat stimulan sistem saraf, amfetamin memiliki efek yang dapat mempengaruhi frekuensi nadi, suhu tubuh, tekanan darah, nafsu makan, konsentrasi, suasana hati dan emosi serta berhubungan dengan kewaspadaan terhadap lingkungan sekitar.

No Bilangan Gelombang $\mathrm{Cm}^{-1} \quad$ Gugus Fungsi




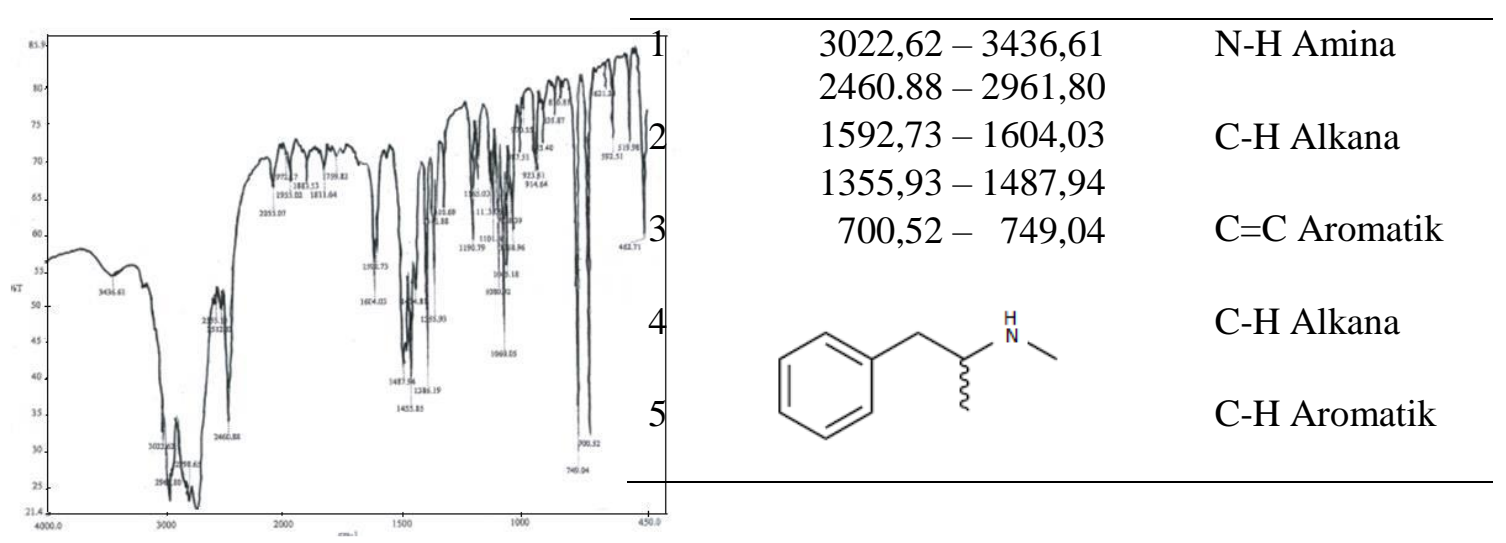

Gambar 3. Spektrum FTIR, Gugus Fungsi dari Struktur Kimia Methamphetamin (Tanaka, 2006)

Untuk mengetahui pemahaman dan pengetahuan dini mengenai narkoba pada generasi muda di desa Mengwi telah dilakukan penyebaran kuesioner salah satu metode dan alat yang dapat digunakan untuk mengetahui awal bagaimana pengetahuan narkoba dan zat aditif di masyarakat. Kuisioner yang dibagiakan secara acak sekitar 30 responden, diberikan sebelum dan sesudah penyuluhan untuk melihat apakah ada peningkatan pemahaman terhadap pemahaman narkoba dan zat aditif. Hasil yang diperoleh dari analisis kuisioner sebelum dan sesudah penyuluhan seperti diperlihatkan dalam Gambar 4.

Hasil Kuisioner menunjukkan bahwa terjadi peningkatan pemahaman narkoba dan zat aditif pada generasi muda di desa Mengwi dari $(79,91 \pm 4,98)$ menjadi $(93,19 \pm 0,17)$ terjadi peningkatan yang signifikan (lebih 10\%). Peningkatan pemahaman juga terlihat dari nilai standar deviasi, awalnya tidak merata menjadi lebih merata pemahaman dari 4,98 menjadi 0,17 . Hal ini terlaksana berkat kerjasama berbagai pihak antara lain Hibah Udayana Mengabdi Universitas Udayana, Desa Mengwi sebagai salah satu Desa yang dipilih dalam program pengabdian ini, pimpinan BNN Kabupaten Badung beserta Staf, dan seluruh masyarakat desa, serta staf dosen program Studi Kimia F.MIPA yang ikut berpartisipasi dalam pelaksanaan pengabdian seperti kegiatan dalam Gambar 5. Hasil ini menandakan bahwa gerakan nasional telah berhasil dilaksanakan dalam skala kecil dalam pengabdian masyarakat ini, namun perlu ditingkatkan di masa mendatang agar semakin banyak desa- desa di Bali yang menjadi sasaran. Sehingga tercipta pemahaman yang sama mengenai Narkotika dan zat aditif dalam masyarakat.

Zat Adiktif lainnya seperti tambahan makanan yang ditambahkan pada masakan bertujuan untuk membuat makanan atau minuman lebih menarik,tahan lama,beraroma untuk menciptakan selera. Peraturan menteri kesehatan RI Nomor 208/Menkes/Per/IV/1985 di antara semua pemanis buatan 
hanya beberapa yang diizinkan penggunaannya. Pemanis buatan yang dimaksud adalah sakarin, siklamat dan aspartame dengan jumlah yang dibatasi dengan dosis tertentu. Meskipun sakarin dan siklamat tergolong dalam bahan tambahan pangan yang diizinkan oleh pemerintah,namun kewaspadaan terhadap penggunaan jenis pemanis buatan tersebut perlu dilakukan. Mengingat tidak semua paham betul tentang bahan tambahan pangan, penggunaannya, dan pengolahan Berbagai efek negatif akan muncul jika penggunaan sakarin dan siklamat yang tidak sesuai aturan yang telah ditetapkan.

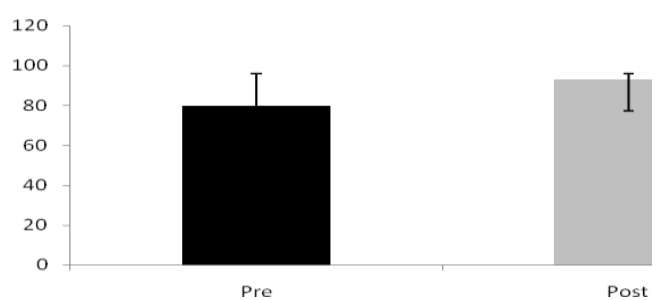

Gambar 4. Hasil Kuisioner pre dan post test
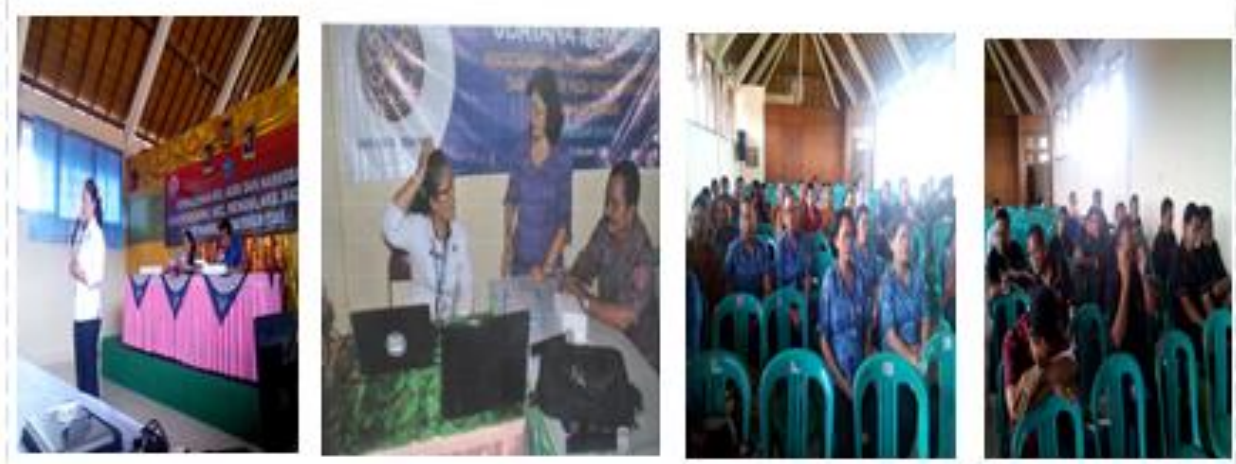

Gambar 5. Foto Kegiatan Pengabdian Pengetahuan narkoba dan Zat aditif

Kafein juga sebagai salah satu zat adiktif, yang sangat disukai di masyarakat tanpa disadari sering diminum sesuai keinginan dan selera, kafein termasuk senyawa stimulan dari sistem saraf pusat dan metabolisme, digunakan secara baik untuk pengobatan dalam mengurangi keletihan fisik dan juga dapat meningkatkan tingkat kewaspadaan sehingga rasa ngantuk dapat ditekan. Kopi merupakan salah satu sumber kafein yang tersebar luas dan dapat diperoleh secara bebas. Pengaruh gaya hidup dan semakin maraknya cafe serta kedai kopi memberikan kontribusi dalam peningkatan jumlah konsumen kopi (Swastika, 2013).

Konsumsi kafein secara rutin dapat menyebabkan terjadinya toleransi. Tanda-tanda dan gejalagejala dari konsumsi kafein secara berlebihan antara lain kecemasan, insomnia, wajah memerah, dieresis, gangguan saluran cerna, kejang otot, berbicara bertele-tele, takikardia, aritmia, peningkatan energy dan agitasi psikomotor. Kafein dapat berinteraksi dengan siprofloksasin dimana mengakibatkan terjadinya penurunan metabolism hepatic kafein sehingga efek farmakologi kafein dapat meningkat. 
Kafein diabsorpsi secara cepat pada saluran cerna dan kadar puncak dalam darah dicapai selama 30 hingga 45 menit. Pada orang dewasa yang sehat jangka waktu penyerapannya adalah 3-4 jam, sedangkan pada wanita yang memakai kontrasepsi oral waktu penyerapan adalah 5-10 jam. Pada bayi dan anak memiliki jangka waktu penyerapan lebih panjang (30 jam). Kafein dapat melewati plasenta dan lapisan darah-otak dikarenakan sifatnya yang hidrofobik. Kafein diuraikan dalam hati oleh sistem enzim sitokhrom P 450 oksidasi kepada 3 dimethilxanthin metabolik, yaitu :

a. Paraxanthine (84\%), mempunyai efek meningkatkan lipolisis, mendorong pengeluaran gliserol dan asam lemak bebas didalam plasma darah. Inilah yang menyebabkan energi tubuh seseorang meningkat setelah minum kafein.

b. Theobromine (12\%), melebarkan pembuluh darah dan meningkatkan volume urin. Theobromine merupakan alkaloida utama didalam kokoa (coklat).

c. Theophyline (4\%), melonggarkan otot saluran pernafasan, digunakan pada pengobatan asma.

Hati merupakan tempat utama dalam proses metabolisme kafein. Masing masing dari hasil metabolisme ini akan dimetabolisme lebih lanjut dan akan dikeluarkan melalui urin. Waktu paruh eliminasi berkisar antara $3-7$ jam dan dapat dipengaruhi oleh berbagai faktor, meliputi jenis kelamin, usia, penggunaan kontrasepsi oral, kehamilan dan merokok. Telah dilaporkan bahwa waktu paruh kafein pada wanita lebih singkat dibandingkan dengan laki-laki.

Contoh analisis kafein secara kuantitatif adalah secara titrasi dengan Kalium permanganat dan spektrofotometri UV-vis melalui kurva kalibrasi standar kafein.

\section{KESIMPULAN DAN SARAN}

Pemahaman mengenai pengetahuan Narkoba dan zat aditif pada generasi muda di Desa Mengwi terjadi peningkatan berdasarkan analisis kuisioner yang dilakukan sebelum dan sesudah pelaksanaan penyuluhan dari BNN Kabupaten Badung. Hal ini menandakan bahwa gerakan nasional pengetahuan narkoba sudah berhasil dilakukan yang pelaksanaannya telah dilakukan di Desa Mengwi. Penyuluhan ini perlu disebar luaskan, dan semakin diefektifkan pelaksanaannya ke Banjar-Banjar di seluruh Bali, agar masyarakat dapat mengatakan tidak mengenai narkoba sesuai sasaran pada Program Pemerintah melalui BNN.

\section{UCAPAN TERIMA KASIH}

Terima kasih kepada UniversitasUdayana atas dan pengabdian PNBP Udayana Mengabdi melalui LPPM, atas kesempatan dan ijin melaksanakan Pengabdian kepada masyarakat dengan kontrak No. Nomor: Nomor: 640 - 83 /UN14.2/PKM.01.03/2016, tanggal 15 Juni 2016.

\section{DAFTAR PUSTAKA}

Hawari, H.D.2001. Penyalahgunaan dan ketergantungan NAZA (Narkotika, Alkohol, dan Zat Adiktif).Fakultas Kedokteran Universitas Indonesia.ISBN 979-496-231-7. Gaya Baru Jakarta.

Lowry WT; Garriot JC. 1979. Forensic Toxicology Controlled Substances and dangerous Drugs, Plenum Press, New York.

Mat H. HO. 1990. Analytical Methods In Forensic Chemistry. Department of Chemistry University Of Alabama at Birmingham, USA. Ellis Horwood, New York.

Moffat AC., Osselton MD., Widdop B. 2004. Clarke's Analysis of Drugs and Poisons in Pharmaceuticals, body fluids and postmortem material. Editor: Galichet LY. Third Edition. London. Pharmaceutical Press.

Mumin A, Kazi F A, Zainal A, Zakir H. 2006. Determination and Characterization of Caffeine in Tea, Coffee, and Soft Drink by Solid Phase Extraction and High Performance Luquid Chromatography (SPE - HPLC). Malaysian Journal of Chemistry, 8: 45-51.

Barlie, F. A. 2005. Clinical Toxicology :Principles dan Mechanisms . Florida: CRC Press 
Norton T R, Lazev A B, Sulivan M J. The "Buzz" on caffeine : patterns of caffeine use in a convenience sample of college students. Journal of Caffeine Research 2011; $1(1): 35-40$.

Swastika K D. Efek kopi terhadap kadar gula darah post prandial pada mahasiswa semester VII Fakultas Kedokteran Universitas Sumatera Utara tahun 2012. 2013.

Tanaka (2006), Manual for Use by National Drug Testing Laboratories, united nations publication, New York. 